\title{
RECREACIÓN, ESPACIO PÚBLICO Y CONFLCITO. Las caravanas festivas de los fanáticos de cumbia de la Ciudad de Corrientes (Argentina)
}

\author{
Ezequiel Ledesma \\ Arquitecto FAU-UNNE. Becario Doctoral CONICET del Instituto de Investigación y Desarrollo en Vivienda \\ IIDVi- FAU UNNE Resistencia, Argentina. Alumno del Posgrado en Antropología Social PPAS-UNaM \\ Posadas, Argentina. \\ Directora de investigación: Dra. Arq. Laura Alcalá. \\ ledes.arq@hotmail.com

\section{RESUMEN} \\ Los seguidores en la Ciudad de Corrientes (Argentina) se presentan como un fenómeno conflicto de más de \\ 15 años de existencia, que se caracteriza por el desplazamiento masivo de cientos de jóvenes fanáticos por \\ las periferias de la ciudad, mientas siguen a grupos de cumbia locales. Este trabajo presenta dos partes: una \\ primera que busca explicar y contextualizar el caso y el tema en estudio a partir de exponer algunos aspectos \\ sobre el fenómeno que se consideran fundamentales; $y$ una segunda parte que expone una primera propuesta \\ de pre-proyecto de tesis.
}

Palabras claves: espacio público- Ciudad de Corrientes - seguidores de cumbia

\begin{abstract}
ABSTRAC
In the Corrientes city (Argentina) los segudiores are a conflictive phenomenon of more than 15 years of existence, which is characterized by the massive transit of hundreds of younger fans through the peripheries of the city, to follow local cumbia groups. This paper presents 2 parts: the first explain and contextualize the case and the subject, starting from exposing some aspects about the phenomenon that is considered raised; the second one exposes a first proposal of thesis pre-project.
\end{abstract}

Key words: public space - Corrientes City- seguidores de cumbia 


\section{INTRODUCCIÓN}

Hablar de "los seguidores" en la Ciudad de Corrientes (Argentina) es hacer referencia a un fenómeno y a un conflicto de más de 15 años de existencia, que presenta aristas sociales, culturales, políticas y urbanoterritoriales, y que está caracterizado por el desplazamiento masivo de cientos de jóvenes fanáticos que siguen a grupos de cumbia locales. Este trabajo presenta dos grandes partes, una primera que busca presenta el caso y el tema en estudio a partir de exponer algunos aspectos del fenómeno, resultados de las primeras exploraciones en campo que fueron trabajados durante el año 2017 en escritos monográficos y en presentaciones a eventos científicos ${ }^{1}$. Esta primera parte busca sentar bases para en una segunda donde se esquematiza una primera propuesta de pre-proyecto de tesis. Esto servirá para poder ajustar las búsquedas en campo, y para poder discutir sobre los aspectos propuestos y las intenciones de relato del futuro trabajo de tesis. Vale aclarar que, en el marco de esta investigación, el espacio público, es entendido como un espacio dinámico que está en permanente formación y resignificación, donde a partir del soporte físico dado, los habitantes realizan sus prácticas cotidianas y expresan su condición social, política y religiosa, ritualizan y modifican determinadas prácticas en virtud de permanentes acuerdos, disputas y conflictos que se establecen y reestablecen entre sí. No se trata de un territorio definido, sino de territorializaciones, de apropiaciones donde cada colectivo se agencia del espacio y le confieren un valor simbólico (Delgado, 2007).

\section{OBJETIVO}

Este escrito se enmarca en el plan de trabajo de una Beca Doctoral CONICET que lleva por título "EI ESPACIO PÚBLICO DE LAS MANIFESTACIONES POPULARES. PRÁCTICAS Y DINAMICAS DE LA POBLACIÓN JOVEN ENTRE EL CENTRO Y LA PERIFERIA DE LA CIUDAD DE CORRIENTES, investigación que sostiene como hipótesis que las manifestaciones populares en el espacio público son una oportunidad para reconocer el andamiaje social que lo dota de significado y que devela los intereses, disputas, acuerdos, costumbres, gustos y las posiciones desde donde cada ciudadano hace uso y habita la ciudad. Esta investigación propone analizar las prácticas y dinámicas que la población joven despliega sobre el espacio público, identificar las manifestaciones populares entre el centro y la periferia, caracterizarlas junto a los grupos que las accionan y que a través de ellas se expresan; propone así, identificar las formas de apropiación y uso del espacio público y analizarlas en relación con las características físicas de éste. En este contexto, el objetivo general del trabajo es presentar el tema, las características y complejidad del caso en estudio, siempre en relación con el tema (usos del espacio público), y a partir de esto proponer algunos elementos de un pre-proyecto de tesis para someterlo a discusiones y ajustes.

\section{MARCO TEÓRICO: ESPACIOS PÚBLICOS Y CONFLICTO}

Esta investigación es producto de la convergencia de varias situaciones que han llamado mi atención, por un lado, una atracción por el fenómeno abordado, por otro el interés por el espacio urbano sus formas de uso y apropiación, y en estrecha relación con éstos el abordaje teórico propuesto por la antropología urbana del Manuel Delgado, y la corriente de propuestas de otros autores que esté recupera. Las tesis de este antropólogo español han sido la que en parte han servido de base del proyecto de esta investigación, y que, sin haber limitado la miradas y búsquedas del trabajo frente a la realidad empírica del campo, han podido orientar la búsqueda y ayudar a alimentar de forma desafiante el abordaje temático. Encuentro en gran parte del trabajo de Delgado una coherencia en relación con el tema y caso propuestos, pero tambien en lo que respecta a mi posicionamiento para abordarlos.

Además de sus ideas sobre temas como la masa, el público, los transeúntes como seres rituales, sobre la persistencia, sobre la negación e intentos de control sobre el conflicto en las calles, el uso y apropiación de los exteriores urbanos, manifestaciones y fiestas en las calles, el aporte fundamental tomado desde su teoría consiste en las discusiones y tensiones que propone sobre el concepto de espacio público, a partir de entenderlo desde diferentes acepciones, desde la práctica y la teoría. Así, esta noción es abordada en algunos de sus trabajos $(2011,2013)$ desde 3 perspectivas posibles: A) como escenario de y para las "relaciones públicas" o "en público", configurando un tipo específico de vida social en el que los concurrentes se someten a las iniciativas y juicios ajenos y conforman configuraciones transitorias, pero estratégicas, protagonizadas en buena parte por desconocidos en un régimen de visibilidad generalizada. Es este el valor que sostiene la tradición interaccionista y microsociológica, de autores como Simmel, Goffman y los integrantes de la Escuela de Chicago. B) Desde la administración política se entiende al EP como el conjunto de espacio de titularidad pública, exteriores urbanos y contenedores institucionales, sometidos a la administración del Estado, siendo

\footnotetext{
${ }^{1}$ Monografías realizadas durante 2017 en seminarios del Programa de Posgrado en Antropología Social PPAS-UNaM (Posadas, Argentina), y un artículo de investigación titulado "La de los seguidores de cumbia en la Ciudad de Corrientes" presentado a las Jornadas de Comunicaciones Científicas y Tecnológicas FAUUNNE 2017.
} 
este último el que debe garantizar su accesibilidad para todos sin excepción, para lo cual legisla y normativiza a propósito de las buenas prácticas que legitiman su disfrute, lo protegen del interés privado y cuidan de su conservación; es el espacio definido y regulado por las leyes y normativas, destinadas a establecer cuáles son sus usos adecuados y aceptables y cuáles deben ser objeto de sanción. De esta acepción se deriva el concepto penal de "orden público"- cuya alteración conlleva consecuencias penales-y que lleva a considerarlo C) desde la filosofía política, atendido como categoría abstracta derivada de la noción ilustrada de publicidad, esfera- en teoría- ideal para la coexistencia pacífica de lo heterogéneo de la sociedad, ámbito de y para el libre acuerdo entre seres autónomos y emancipados que se vinculan a partir de pactos reflexivos permanentemente reactualizados, individuos libres e iguales que critican, valoran y fiscalizan los poderes políticos, y que se entienden a partir de su capacidad para argumentar y pactar entre sí. Es el "ámbito público", donde se despliegan los principios éticos de la civilidad, la ciudadanía y demás virtudes en que funda su posibilidad la democracia igualitaria. Sus referentes serían H. Arendt, R. Koselleck, J. Habermas.

A ese espacio público como categoría política, que organiza la vida social y la configura políticamente, le urge verse ratificado como lugar en que sus contenidos abstractos abandonen la superestructura en la que estaban instalados y bajen literalmente a la tierra, se hagan "carne entre nosotros", así procura dejar de ser un espacio concebido y se quiere reconocer como espacio dispuesto, visualizado. Esto es proceso por el cual una calle o una plaza sean algo más que simplemente eso; deben ser el proscenio en que esa ideología ciudadanista, y donde ese concepto de EP exige ver cumplida la realidad que evoca- el desvanecimiento de las desigualdades y su disolución en valores universales de orden superior-, una ficción nominal concebida para inducir a pensar y actual de cierta manera y que urge verse instituida como realidad objetiva. En este sentido el EP consiste según delgado en una "idea dominante", en el doble sentido de ideas de quienes dominan y de ideas que están concebidas para dominar: se trata de "disuadir y persuadir de cualquier disidencia, cualquier capacidad de contestación o resistencia y- tambien por extensión- cualquier apropiación considerada inapropiada de la calle o de la plaza, por la vía de la violencia si se es preciso, pero previamente y sobre todo por una descalificación o una deshabilitación que, en nuestro caso, ya no se lleva a cabo bajo la denominación de origen subversivo, sino de la mano de la mucho más sutil de incívico, o sea, contraventor de los principios abstractos de la buena convivencia ciudadana" (2013: 26-27).

\section{Manifestaciones populares}

Como se ha dicho, esta investigación tambien partió del interés por una serie de sucesos que acontecen en el espacio público de Corrientes, y que fueron agrupados bajo la categoría de "manifestaciones populares". Lo popular, es un concepto polisémico que, entendido desde diferentes paradigmas, ha funcionado como un calidoscopio de significados según el lugar y momento histórico. Mientras que en el contexto latinoamericano lo popular está frecuentemente referido a las prácticas culturales de los sectores subalternos (González C. et al, 2016), también se asocia a la tradición, al folclore, a la sociedad de masas y clase media, a los jóvenes (Míguez y Semán, 2006). Míguez y Semán critican la búsqueda determinista de lo popular, como si fuera una esencia predeterminada, y proponen construir una matriz a base de rasgos prototípicos, subyacentes y extraíbles de una casuística, que al igual que los rasgos fenotípicos de una familia, que sin necesidad de repetirse en su totalidad, aparezcan en una cantidad suficiente para identificar a una serie de manifestaciones como pertenecientes a un mismo tipo (populares). En esta investigación, la matriz partió de la confección de una lista de manifestaciones que algunos correntinos entrevistados identificaron y justificaron como populares; al comparar y sinterizar estas prácticas fue posible obtener los siguientes rasgos identificatorios de lo popular en Corrientes: ser actividades masivas, comunes a la población en general (sin referencia directa a las clases bajas), practicadas con recurrencia, reconocidas como costumbres, que se relacionan con lugares de la ciudad, con tradiciones que definen una "identidad correntina", y que son promovidas por propia voluntad.

Entre algunas de las manifestaciones populares que transitan las calles de la ciudad se encuentran los carnavales "oficiales" y "barriales", las procesiones religiosas al interior de la ciudad y hacia otras localidades, las tradicionales salidas y paseos por el circuito de espacios públicos del centro y costanera de la ciudad. En este contexto de manifestaciones y practicas centradas en el transito tradicional o ritual en el espacio urbano, "los seguidores" son conocidos por ser un fenómeno que consiste en salidas festivas, realizadas durante las noches del fin de semana que toman la forma de extensas caravanas, y donde cientos de jóvenes recorren las calles de la ciudad siguiendo, la mayoría de ellos en motocicleta, el circuito de presentaciones de bandas de cumbia locales. Entre estas bandas las más populares son Yiyo y los Chicos 10 y Eclip'c, que son las que definen los dos grandes bandos de identificación de algunos seguidores, los seguidores de Yiyo, o yiyeros y los seguidores de Eclip’c o eclipceros. 


\section{MÉTODO}

Este trabajo es encarado desde la etnografía, entendida en una triple acepción, como enfoque (1), una concepción y practica del conocimiento que busca comprender los fenómenos sociales desde la perspectiva de sus miembros, actores o agentes. La etnografía como método (2) con actividades que suelen designarse como "trabajo de campo" donde son los actores los privilegiados a la hora de expresar el sentido de los hechos y no el investigador, quien debe someterse y partir de una ignorancia metodológica para ir aproximándose a la realidad que estudia para conocerla, recorrer el arduo camino del des-conocimiento al re-conocimiento. $\mathrm{Y}$, la etnografía como texto (3) que implica la descripción textual del comportamiento de una cultura particular, resultante del trabajo de campo (Guber, 2012).

\section{CIUDAD DE CORRIENTES, RELATOS DEL ESAPCIO}

Corrientes, es la ciudad capital de la provincia homónima del noreste de la Argentina, que según el censo 2010 cuenta con una Población de 346.334 habitantes (INDEC, 2010). Corrientes fue fundada en 1588 por adelantados españoles en las costas del Río Paraná, situación que estableció el característico emplazamiento geográfico de su casco fundacional, de origen hispano, a orillas del Rio Paraná. A partir de este centro histórico, administrativo y comercial, Corrientes ha presentado un desarrollo en abanico hacia el sur y este del territorio, promovido desde la década de los '70 fundamentalmente por la construcción de barrios periféricos financiados en su mayoría por el Estado. Presenta un área central que se identifica como "dentro de las cuatro venidas", que además es el frente, fachada o la cara visible de la ciudad por concentrar los espacios públicos de mayor calidad que aprovechan el paisaje costero. El crecimiento de la ciudad podría entenderse como la expansión centrípeta desde ese centro, de grandes vías de circulación que junto a las unidades habitacionales identificables a partir de su homogeneidad física interna (los barrios) van definiendo una forma de ocupación que puede ser asimilable a la estructura de una telaraña. En Corrientes, el centro y la periferia constituyen territorios con correspondencias geoespaciales y sociales específicas, que dan lugar a imaginarios, identidades y representaciones simbólicas que abonan a la identidad construida de sus habitantes. Son áreas diferencialmente recorridas y usadas por los habitantes: el centro es la referencia simbólica de la ciudad, vinculada al poder económico y gubernamental, y el lugar de residencia de los sectores medio-alto y alto y receptor temporario de los sectores medio-bajo y bajo en sus desplazamientos obligados cotidianos laborales, en sus desplazamientos ocasionales festivos, recreativos y de ocio, así como en sus desplazamientos reivindicativos. Los barrios (como sinónimo de periferia), en cambio, son principalmente recorridos por sus propios residentes y son desconocidos fuera de su entorno inmediato.

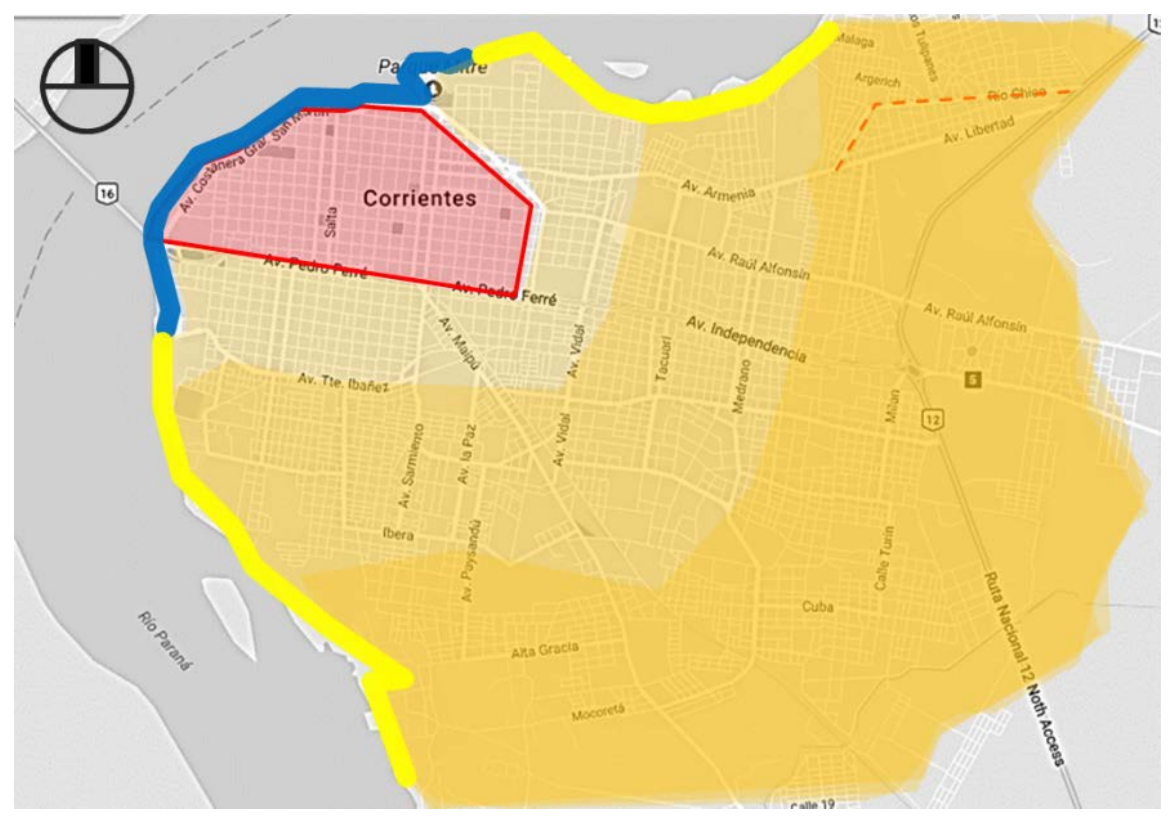

\section{Centro y periferia de Corrientes}

Rojo: área reconocida como central; naranja: anillos de periferia, azul: borde costero considerado frente, amarillo: bordes costeros no considerados frentes de la ciudad. (Elaboración propia sobre imagen de Google Maps)

Según Michael De Certeau las estructuras narrativas poseen valor de sintaxis espaciales que, a partir de toda una panoplia de códigos, de conductas ordenadas y de controles, producen geografías de acciones. Los relatos del espacio son recorridos de espacios, que organiza los andares, que hacen el viaje, antes o al mismo tiempo de que este sea ejecutado, y todo relato es un relato de viaje, una práctica del espacio, así, no 
constituyen sólo un suplemento de las enunciaciones de las circulaciones, son operaciones espacializantes que organizan los lugares a través de los desplazamientos que "describen", organizan lugares haciendo con ellos frases e itinerarios. (De Certeau, 2000). A partir de las características físicas de la ciudad y de su implantación geográfica, se desarrollan una serie de retoricas que explican, relatan, y visibilizan formas de entender el espacio en el uso cotidiano de sus habitantes. Así quedan definidos y producidos por contraposición 2 posibles conjuntos de significaciones. Pero estas indicaciones de ubicación en el espacio no solamente exponen una inocente relación de los lugares en el territorio, sino que sobre todo ayudan a divisar marcas y valoraciones sobre lo que se entiende bueno y lo malo, lo deseable y lo indeseable, seguro peligroso... en el contexto de social de los correntinos. Así por un lado queda definido por un lado la idea de centro, "dentro de las cuatro avenidas", del centro como inicio de algo, de lo cercano, de costanera, de frente, de adelante, de altura (de costa alta no inundable) como referencia a condiciones deseables, en contraposición a las ideas de periferia, de barrio, de "fuera de las cuatro avenidas", del afuera, del atrás, del final, del límite, del fondo, de lo bajo (costas bajas inundables). Por otro lado, el territorio tambien suele ser explicado a partir de posiciones y gestos de adentro y afuera, de entrar y salir, de adelante y atrás a partir de las áreas menores en las que se divide el territorio los (barrios) y de las grandes vías de circulación que los definen y limitan (las avenidas).

\section{SEGUIDORES Y SEGUIDILLA}

"Los seguidores" constituye un fenómeno con más de 15 años de existencia en la ciudad de Corrientes y ampliamente conocido por todos los correntinos por estar asociado a jóvenes de la periferia, a la movida cumbiera y a una serie recurrente de delitos. A pesar de ser un fenómeno de relevancia sociológica, urbanoterritorial, y hasta político no presenta estudios ni investigaciones que lo aborden seriamente ${ }^{2}$.

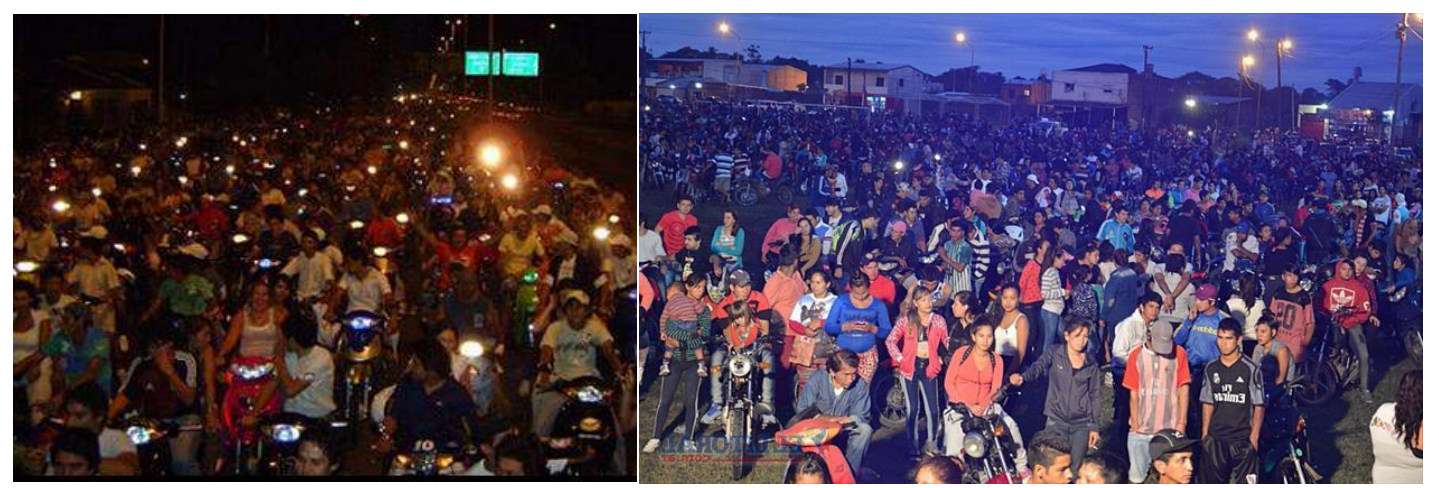

\section{Las seguidillas}

Izq: Caravana de seguidores por Av. Pedro Ferré, año 2012. Dcha: seguidores de bandas de cumbia en el recital Corrientes Cumbia (Barrio San Antonio Oeste), año 2017. Fuentes: https://www.ellitoral.com.ar/

Los seguidores son considerados por el imaginario colectivo como una amenaza, visión que es condicionada por la tendencia de la prensa a mostrarlo como un problema que necesita ser controlado por el accionar de las fuerzas de seguridad y de los gobiernos locales. La revisión de las casi 400 notas online disponibles en uno de los diarios de la ciudad (https://www.ellitoral.com.ar) desde el año 2008 hasta el mes de mayo de 2017 que comentan algún hecho relacionado a los grupos de seguidores en estudio, hace posible reconocer la relevancia del fenómeno a partir de la variedad de aristas temáticas que implica, de los actores implicados, y de la diversidad de hechos conflictivos mencionados ${ }^{3}$.

A grandes rasgos durante este periodo de casi 10 años (2008 a 2017) los seguidores se presentan como un foco de problema constante, una amenaza para el resto de la "sociedad correntina" a partir de su comportamiento "desmedido e invasivo". Pero el problema no es el fanatismo en sí, el problema se constituye cuando los seguidores forman y circulan en grupos o en caravanas que siguen a las bandas, que son las

\footnotetext{
2 Existe una referencia de un trabajo sobre los seguidores, que no ha sido localizado hasta la fecha: "Una visión académica del fenómeno tropical de los seguidores de Yiyo"

http://www.ellitoral.com.ar/226734/Una-vision-academica-del-fenomeno-tropical-de-los-seguidores-de-Yiyo (recuperado el 25 de junio de 2017)

3 Algunas aclaraciones pertinentes: la razón de la elección del diario El Litoral radica en ser el medio de comunicación con mayor volumen, variedad y antigüedad de notas referidas a los seguidores. El procedimiento de búsqueda consistió en reunir las notas que surgieran como resultado de las palabras "seguidor Yiyo", "seguidor Eclip'c", "seguidor", "Cumbia", "Corrientes Cumbia", con una cantidad superior a las 450 notas coincidentes. Posteriormente se verificó la relación de cada una de las coincidencias al caso de los seguidores obteniendo finalmente un total de 387 notas recuperadas hasta mayo de 2007.
} 
protagonistas durante las noches de los fines de semana, accidentes de tránsito relacionados a la motocicleta, al consumo excesivo de alcohol, desatención de las normas de tránsito, situaciones de ruido molestos, vandalismo amenazas a otros transeúntes o vecinos, robos, enfrentamientos entre bandos de seguidores o con la policía, entre otros hechos que en ocasiones han resultado con heridos graves o con la muerte de alguno de sus involucrados ${ }^{4}$.

En estos conflictos como actores, además de los grupos de seguidores (siempre anónimos) y de los grupos y "lideres" de cumbia, aparecen los vecinos de la ciudad afectados directamente por su actividad. Con el objetivo de "contener, controlar, desactivar las caravanas" aparecen las fuerzas de seguridad y de orden público como son la Policía de Corrientes, los Inspectores de Transito, y el Grupo de Rápida Intervención Motorizada (GRIM), y en algunos casos hasta se nombra la intervención de la Gendarmería Nacional y Prefectura. Por otro lado, "buscando soluciones" aparecen constantemente diversos funcionarios públicos, tanto del Gobierno Provincial pero fundamentalmente del Gobierno Municipal.

En este contexto, hasta el año 2014 son frecuente las reuniones entre Municipio y las bandas de cumbia para buscar acuerdos y dispositivos para controlar la actividad de las caravanas de seguidores, también es frecuente una serie de controles de lugares, horarios y permisos aplicados a la actividad de las bandas con el fin de limitar situaciones que puedan fomentar el mal comportamiento de sus fanáticos. Ante esto las bandas reclaman que necesitan "salir a tocar para poder vivir", y reconocen que su popularidad y éxito radica en la existencia de sus seguidores empero intentan desligarse públicamente de ellos, con quienes dicen no tener relación directa, no poder controlarlos y declaran tampoco excitar su mal comportamiento. Estas noticias sobre situaciones conflictivas disminuyen hacia el año 2015 (cuando también disminuye notablemente la cantidad de notas referidas al fenómeno) y empiezan a aparecer menciones a los recitales del Corrientes Cumbia, organizados por el Gobierno de la Provincia en diversos barrios de la ciudad, y donde tocan numerosas bandas de cumbia locales con masiva concurrencia de vecinos. La contratación de algunos de estos grupos de cumbia para las campañas publicitarias de ambos gobiernos (del que el Corrientes Cumbia es parte) 5 y la postulación de uno de los lideres cumbieros como concejal por un partido político hacia el año 20136, no puede dejar de considerarse como muestras de la existencia de una relación - conflictiva- entre cumbia y política.

La caravana de seguidores sigue las trayectorias ${ }^{7}$ de la combi que transporta a Yiyo y a su banda, replica sus desplazamientos y paradas. La banda a su vez define sus movimientos por la ciudad a partir de un itinerario de contrataciones previamente organizado que les obliga a circular por una serie de localizaciones específicas (la mayoría de las veces casas particulares de la periferia). Esta sucesión de seguidos es completada por un último personaje que per-sigue a los seguidores: las patrullas de la policía de Corrientes y otras fuerzas, que tratan de detener y dispersar las prácticas de los grupos de seguidores. La lógica de esta secuencia fue puesta en evidencia cuando el municipio capitalino comenzó a intervenir en la actividad de los grupos de cumbia con el fin de combatir las caravanas de sus seguidores ${ }^{8}$. Por otro lado, evidencia también que la existencia misma de la caravana depende de la salida del grupo de cumbia, de que ésta deba cumplir con algún circuito de presentaciones que la obligue a circular por las calles de la ciudad, para poder ser seguida. La banda es el objeto que los seguidores siguen y es la razón que los congrega como tales; en otras palabras, si el grupo de cumbia no tiene presentaciones, si no se ve obligado a estar y circular por las calles de la ciudad, si está ausente en el afuera, la actividad de los seguidores como tal pierde sentido.

Es frecuente que la prensa hable de "las caravanas" de seguidores para referirse a los grupos de jóvenes que siguen a Yiyo"; pero entre los mismos seguidores estos grupos reciben el nombre de "la seguidilla", que es otra expresión propia de este ámbito que al igual que seguidor, está construida a partir de la idea o de la

4 Título de nota: "La muerte de Kukito, el utilero de Yiyo, otro crimen que quedó en la impunidad" http://www.ellitoral.com.ar/283465/La-muerte-de-Kukito-el-utilero-de-Yiyo-otro-crimen-que-quedo-en-la-impunidad

(recuperado el 22 de junio de 2017)

5 Título de nota: "Tassano visitó varios barrios y participó del Corrientes Cumbia en el San Antonio Oeste"

http://www.ellitoral.com.ar/460002/Tassano-visito-varios-barrios-y-participo-del-Corrientes-Cumbia-en-el-San-Antonio-

Oeste (recuperado el 22 de junio de 2017)

6 Título de nota: "Un cumbiero peronista se lanza como precandidato para 2013"

http://www.ellitoral.com.ar/217918/Un-cumbiero-peronista-se-lanza-como-precandidato-para-2013

(recuperado el 25 de junio de 2017)

${ }^{7}$ De Certeau recurre a categorías como trayectoria o transcurso, para subrayar cómo el uso del espacio público por los viandantes implica la aplicación de un movimiento temporal en el espacio, es decir la unidad de una sucesión diacrónica de puntos recorridos, y no la figura que esos puntos forman sobre un lugar supuesto como sincrónico (Delgado, 1999)

8 Título de nota: "Prohíben la actuación de grupos de cumbia en los domicilios particulares" en www.ellitoral.com.ar (recuperado el 22 de junio de 2017) 
acción de seguir. Algunas expresiones de campo que ejemplifican su uso son "...tenés que ir y buscar nomas la seguidilla...", "...estábamos en la seguidilla...", "... está todo bien hasta que la policía se mete en la seguidilla..." Además de dar nombre e identificar al grupo de seguidores, la seguidilla puede ser entendida como un espacio específico (donde se puede entrar y estar) pero que no posee límites físicos o construidos, y que es definido como tal por el grupo de individuos y de su actividad, quienes mantienen distancias próximas entre sí, ayudando a definir la cohesión interna del grupo y a la vez la diferencia con el afuera, con lo que queda excluido del grupo-espacio.

Los sujetos de la seguidilla son a la vez integrantes y definidores de ésta, son parte del mismo espacio que ellos están definiendo. Es un espacio de agregación, es el espacio donde los seguidores se encuentran para seguir a Yiyo. También es el ámbito donde la identidad de seguidor puede ser legitimada como tal, donde un sujeto cualquiera puede transformarse en seguidor o ser considerado como tal por sus pares a partir del haber seguido a Yiyo. Los seguidores hacen la seguidilla, y la seguidilla hace a los seguidores. Pero la particularidad de la seguidilla es no ser un espacio estático y estable que mantiene en el tiempo una localización fija. Es un espacio que, debido a las características de sus componentes - por estar formado por individuos que buscan estar en movimiento para seguir a alguien-, se caracteriza por encontrarse en un estado de tránsito inminente y de presentar constantes cambios de ubicación en el mapa de la ciudad.

\section{La noche y la periferia}

Los seguidores realizan sus salidas habitualmente en horarios nocturnos, durante las noches de viernes y sábado; y si bien las noches del fin de semana se observa mayor actividad que otras noches, esta se concentra principalmente en espacios públicos del centro y de la avenida costanera de la ciudad. De forma contraria, en los sectores que no son centro, que se localizan afuera de las cuatro avenidas que delimitan el área central de la ciudad, que son llamados, "barrios" (en oposicional centro) o "periferia", la ciudad es otra diferente a la diurna, las calles se vacían de gente, la ciudad se dice muerta, la gente permanece dentro de sus casas y evita salir (muchos para protegerse de amenazas como las que los mismos seguidores representan).

Es durante las noches, y en las áreas consideradas como la periferia de la ciudad, por los márgenes donde los seguidores circulan- o por lo menos por donde intentan mantener sus recorridos al seguir a Yiyo- con el fin de poder evadir los controles policiales que se concentran en las áreas centrales y costeras de la ciudad. Si bien los horarios de salida y las áreas transitadas dependen de forma directa del itinerario de las bandas de cumbia, estas condiciones no dejan de ser componentes fundamentales de la situación de margen que caracteriza a la actividad del grupo de seguidores. "... tampoco nos metemos en el centro para no hacer mucho ruido, porque si no nos ven no nos joden", comenta un seguidor, indicando talvez, que para poder pasar desapercibidos y poder seguir realizando sus salidas, los seguidores tampoco buscan aparecer o ser vistos en el centro de la ciudad, espacio donde quedarían expuestos a las fuerzas de seguridad, pero también a la prensa y con esta al resto de los correntinos.

\section{Mapeo seguidor}

Entre las actividades realizadas en el trabajo, me interesa comentar una experiencia de campo que consistió en una entrevista y un mapeo junto a un seguidor de Yiyo (Esteban), y donde el plano de la ciudad de Corrientes funcionó como disparador de tópicos en relación a su experiencia en la ciudad, a los barrios y a sus recorridos. Junto a Esteban marcamos los barrios donde se presentan las bandas de cumbia y por donde los seguidores circulan (diferenciando los barrios según la frecuencia de las presentaciones); se definieron también otras áreas de presencia policial por donde los seguidores no circulan; y referencias de localidades próximas que también frecuentan. Finalmente, estas áreas fueron cosidas, puestas en práctica a partir de la gráfica del recorrido de una típica noche de "salida".

Basado en estos datos, el territorio de Corrientes y localidades aledañas puede ser dividido en 4 áreas. El área 1, que coincide con el centro comercial-administrativo de la ciudad, es de escasa concurrencia debido a la escasez de presentaciones de los grupos (generalmente en salones de fiesta). Tampoco circulan por esta área, que cuenta con los espacios públicos más concurridos y de mayor visibilidad de la ciudad (como la Av. Costanera) debido a la fuerte presencia policial. El área 2, es un medio anillo que cruza el centro de la ciudad de costa a costa, formado por barrios que en su mayoría son de producción estatal y es donde reside gran cantidad de los fanáticos y donde los grupos y seguidores localizan su mayor actividad en fiestas privadas realizadas en casas particulares. El área 3 sobre los límites de la ciudad, es aquella donde la actividad, sin perder intensidad, se concentra en algunos barrios. Por fuera de la ciudad se define el área 4 donde la actividad se desplaza hasta localidades próximas o en "paradas por la ruta", en casas particulares, fiestas masivas, populares o religiosas. Algunas de estas son parte de las presentaciones de cualquier fin de 
semana, e implican la irrupción de los seguidores en el tránsito y en los controles en las rutas. Entre las localidades más frecuentadas están Riachuelo, San Luís del Palmar (a unos 30km); otras son Empedrado, Santa Ana de los Guácaras, Paso de la Patria, Itatí (a unos 70km).
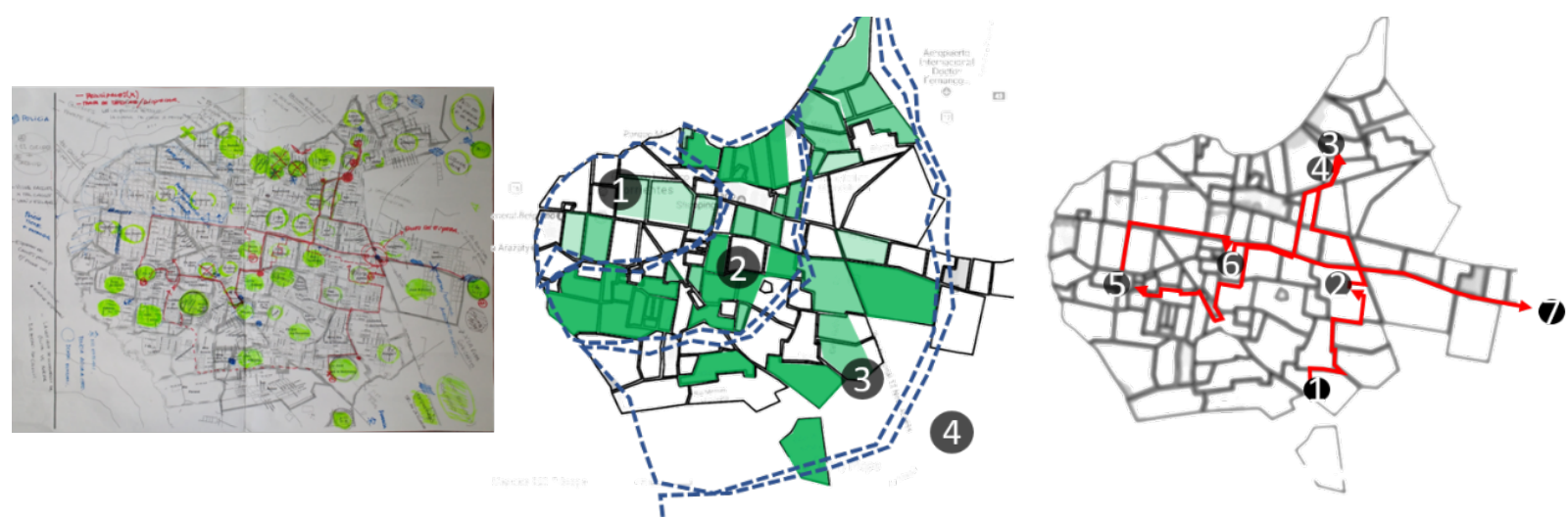

Circuitos seguidores en la ciudad

Izquierda: base cartográfica original de mapeo colectivo junto a seguidor. Medio: intensidad de concurrencia por barrios y definición de sectores de la ciudad. Derecha: recorrido modelo de la seguidilla.

(Elaboración propia en base a datos obtenidos en el mapeo)

A partir de estas prácticas y tránsitos, la ciudad es susceptible de ser dividida en estas 4 áreas, entre las que el contraste se concentra entre el territorio formado por las áreas 2, 3 y 4 (considerada periferia de la ciudad y por donde los seguidores circulan), frente a el área 1 (considerada centro de la ciudad y por donde los seguidores usualmente no circulan). Así, existen dos territorios diferentes, contrastantes, definidos por la presencia o la ausencia de los tránsitos de los seguidores (que a la vez se encuentran definidos por las condiciones que cada área presenta). Como ya se ha comentado los seguidores tratarían de escabullirse de los controles policiales y de ser vistos en lugares donde serían foco de atención pública.

El recorrido comentado por Esteban, además de resaltar los barrios frecuentemente visitados por los seguidores, muestra que es la avenida el espacio por donde la seguidilla habitualmente circula entre presentaciones. En este sentido, Esteban comenta "Generalmente nos movemos por las avenidas, porque es más cómodo y es por donde la combi de Yiyo va, y ahí vamos entrando a los barrios donde está tocando, cuando termina salimos del barrio hacia alguna otra avenida para ir hasta la próxima presentación..." Así, la avenida, además de ser el espacio de tránsito para los seguidores, y de separar barrios entre sí, es también el espacio que separa los territorios de presencia y de ausencia de los seguidores (diferenciados aquí como el centro y los barrios o periferia).

Siguiendo a Bartolomé, la frontera entre estas áreas podría ser entendida como un límite que tendrían la capacidad de contener o filtrar los flujos que provienen del exterior, a la vez que permitir la libre circulación de los flujos internos, quedando así constituido por el "choque" de los flujos internos y externos, cuyo contacto o confrontación se registra en la zona fronteriza entre ambos. (Bartolomé, 2006). En los relatos de Esteban, la avenida, por un lado, parece ser el afuera, afuera de un adentro que queda representado por el barrio. Por otro lado, la avenida es parte del suelo urbano destinado a la actividad de circular, que como parte de la estructura vial de la ciudad ésta hace posible los desplazamientos en la ciudad, pero es también un espacio que separa otros espacios, es un entre-barrios o un entre-áreas.

Una salida habitual de los seguidores detrás de las bandas puede durar hasta $12 \mathrm{hs}$ (inicia 20:30hs) en un circuito de hasta 7 presentaciones. Entre la salida y vuelta a casa los seguidores recorren unos $30 \mathrm{~km}$ dentro de la ciudad y hasta $60 \mathrm{~km}$ en ruta. Esteban complementó estos números con anécdotas que detallaron cuestiones internas de "la movida", sobre las formas de usos del espacio viario al circular o en las paradas en calles de barrios, fuera de alguna casa particular donde el grupo seguido se presenta. Atribuyó los daños y robos en el paso de las caravanas a "infiltrados" que aprovechan la masa pero que "no van a seguir a las bandas". Por otro lado, los temas recurrentes que sostuvieron su relato fueron la experticia requerida en el manejo de la moto para "poder zafar" de ciertas situaciones y la relación de los seguidores con la policía. Según Esteban, la policía los "persigue" por ser seguidores, por ser jóvenes que andan en motos y de forma masiva, pero justifica que "todo se descontrola cuando la policía aparece, tenés que rajar porque desde la camioneta te tiran balas de goma, entonces la moto te permite meterte por la vereda contramano y cosas así". Detalló cómo estudia los espacios por donde circula para saber cómo escapar ante imprevistos, los lugares donde la policía los intercepta, y estrategias para evitar a los patrulleros. 


\section{PRE-PROYECTO DE TESIS}

Después de la exploración por aspectos del fenómeno, esta segunda parte propone algunos elementos de la tesis. El objetivo es objetivarlos, organizarlos, someterlos a discusión y critica, y que más allá de llegar a mantenerse en un escrito final, fundamentalmente puedan servir en el desarrollo mismo de la investigación.

\section{TITULO}

FIESTA, ESPACIO PÚBLICO Y CONFLCITO. Las prácticas de los seguidores de cumbia en la Ciudad de Corrientes (Argentina)

\section{PREGUNTA DE INVESTIGACIÓN}

A partir de los intereses teóricos presentados al comienzo del trabajo, una posible pregunta de investigación podría consistir en ¿Qué papel juega el espacio público de la Ciudad de Corrientes en las practicas festivas de los seguidores de cumbia? Esta cuestión puede ser desarmada en otras varias: ¿Qué relaciones se establecen entre el espacio público y estas prácticas? ¿Cómo usan y significan los seguidores el EP? ¿Qué obstáculos o posibilidades encuentran los seguidores en el espacio público de la ciudad de corrientes para desarrollar sus prácticas?

\section{PROPUESTA DE ASPECTOS DESCRIPTIVOS A ABORDAR Y DE LÍNEA DE RELATO}

A continuación, se propone una posible estructura de tesis que busca 2 objetivos fundamentales, de exponer a discusión: por un lado 1) las posibles partes de la tesis, a partir de una lista de aspectos de carácter descriptivo que considero fundamentales amparar en el abordaje del fenómeno tratado; y por otro 2) proponer un orden de estas partes en la construcción de un relato de temas consecutivos.

Los aspectos descriptivos elegidos surgen de las primeras experiencias de campo realizadas desde marzo de 2017, y responden fundamentalmente a los intereses temáticos de esta investigación (usos del espacio de la ciudad). En el marco de la escritura final de tesis estos aspectos podrían ser desarrollados como capítulos particulares, agrupados y confinados en un mismo capítulo, o hasta descartados, según vayan requiriendo los intereses y búsquedas en el proceso de investigación.

En relación con la línea del relato vale aclarar algunas intenciones latentes. Se buscará 1) avanzar desde lo general a lo particular; 2) presentar al fenómeno y posteriormente introducir su relación con el resto de la sociedad correntina (primero ellos, posteriormente ellos y los otros, o el resto de los actores y el medio); 3) presentar las características del medio físico, y posteriormente la práctica que lo practica, para finalmente ver la relación entre ambos. Por último, y considero que más importante, 4) exponer primero la caracterización del fenómeno, su funcionamiento y partes, para posteriormente avanzar sobre las relaciones, conflictos y tensiones que se establecen en el contacto con el resto de los actores en cuestión.

Estos títulos, que buscan abordar descripciones de diversos aspectos del fenómeno, servirán como materia prima y disparador para el desarrollo de una serie de aspectos temáticos, analíticos, teóricos... Así, se buscará reflexionar sobre tópicos como centro y periferia, sobre marcas y estigmatizaciones sociales, espacios y sujetos representados como amenazas, relaciones y cruces con otras manifestaciones y con estructuras de pensamiento históricas, etc.

\section{1) INTRODUCCIÓN E HISTORIA DEL FENÓMENO}

Esta parte busca ser una introducción a los temas tratados en el trabajo a partir de una breve reconstrucción histórica del fenómeno que exponga sus características principales.

\section{2) PRESENTACION, ENTRADA A CAMPO Y ETNOGRAFÍA DEL TRÁNSITO}

¿Quién es el que investiga, el que mide y comunica la experiencia del campo?

¿Qué relación mantengo con el fenómeno? El porqué de la elección del tema y del caso en estudio

Sobre las dificultades de acceso a campo, ¿Cómo logré llegar al campo? ¿Cómo se lo aborda? Sobre las dificultades de abordar desde la etnografía el caso en estudio.

\section{3) MARCO TEORICO: FIESTA, NOMADEOS Y ESPACIO PÚBLICO}

Discusiones sobre las concepciones de espacio público, de centro y periferia.

Sobre usos y prácticas en espacio público. Sobre la fiesta en la calle, la masa, los tránsitos rituales.

\section{4) EL ESPACIO PÚBLICO DE LAS MANIFESTACIONES POPULARES EN LA CIUDAD DE CORRIENTES}


Caracterización del espacio urbano y del espacio público de la Ciudad de Corrientes. Panorama sobre las formas de uso desplegadas en el espacio público de la Ciudad de Corrientes, y específicamente las prácticas ociosas de los jóvenes.

5) GRUPOS DE CUMBIA, SEGUIDORES Y SEGUIDILLA.

Abordar las características básicas del fenómeno, de las practicas seguidoras, y del grupo de sujetos llamado seguidilla. ¿Qué o cómo es la seguidilla? ¿Cuál es su dinámica de formación? ¿Cómo se organizan?

¿Qué es un seguidor? ¿Cómo se hace un seguidor? ¿Qué es ser seguidor?

La seguidilla como un espacio espontaneo de producción de identidad seguidora.

Discusiones y relaciones en torno a los conceptos de joda, de fiesta

\section{6) LA MOTO: MEDIO DE MOVILIDAD CARACTERÍSTICO}

Sobre la movilidad característica de los seguidores, pero tambien movilidad cotidiana.

¿Alguien compra una moto para seguir a Yiyo?

Las significaciones del transporte

7) TERRITORIOS Y CIRCUITOS SEGUIDORES. ENTRE EL CENTRO Y PERIFERIA.

¿Cómo circula por la ciudad? ¿por dónde circula? ¿Cuál es su lógica?

¿Cómo usan y significan el espacio de la Ciudad de Corrientes?

Discusiones y relaciones en torno a los conceptos de salida, de vuelta, entrar-salir, adentro y afuera.

La práctica definiendo los espacios de centro y periferia de la ciudad.

8) OPINIÓN PÚBLICA SOBRE EL FENÓMENO. EXPLORANDO EL CONFLICTO.

Revisión del tratamiento del fenómeno en los medios de prensa locales ¿qué dicen sobre el fenómeno? ¿Cómo lo muestran y comunican?

Relevamiento de la opinión general sobre el fenómeno, compartida por la sociedad correntina: lo que los correntinos saben y dicen sobre ellos.

¿Por qué el fenómeno resulta conflictivo? ¿Dónde radica el conflicto? ¿Conflictivo para quienes?

¿Qué representa la seguidilla y los seguidores para el resto de los correntinos? Los seguidores son entendidos como una amenaza que asecha desde la periferia, desde afuera. La amenaza al centro de la ciudad al centro de la sociedad.

A partir de este capítulo se comienzan a exponer las relaciones de los seguidores con su contexto social; de esta forma se evita analizar el fenómeno de forma aislada, como si de una tribu se tratara, sin relación con su medio directo.

\section{9) ACCIONES ANTE EL CONFLICTO: SEGUIDORES, GOBIERNOS Y FUERZAS DE SEGURIDAD}

Retoricas y acciones frecuentes y constantes de los gobiernos local y provincial ante las prácticas de los seguidores.

El accionar de las fuerzas de seguridad, formas de intervención, lógicas de intervención, ¿Cómo se justifican? Intervenciones en la cadena de grupos de cumbia y seguidores.

\section{0) EVADIR EL CONTROL. ESTRATEGIAS DE ANONIMATO Y FUGA}

Sobre las estrategias que despliegan los seguidores para poder mantener su práctica.

Algunas estrategias: medios de comunicación cerrados, control sobre la circulación de información, control sobre la disponibilidad de información, búsqueda de apariencia anónima dentro de la seguidilla, estrategias de fuga...

\section{1) CUMBIA, POLÍTICA Y MASA. GESTIÓN PÚBLICA DE RECITALES}

Sobre como los gobiernos buscan aprovechar la masividad del grupo de fanáticos a partir de la organización de recitales de cumbia, donde parte de las mismas prácticas que se combaten por considerarlas conflictivas (puntos $7,8,9$ ) resultan legitimadas, gestionadas y transformadas en ámbitos desconflictuados.

\section{2) CONCLUCIONES Y REFLEXIONES FINALES}

Conclusiones sobre el papel del espacio público en la relación entre practicas seguidoras y el resto de los correntinos.

Posibilidad de lograr reflexiones que excedan el tratamiento del caso: reflexionar sobre los límites de lo permitido en el EP de la ciudad de Corrientes, variables de la que depende este rango. ¿Por qué ellos no pueden y otros sí?

\section{HACIA UNA HIPÓTESIS}


A partir de lo expuesto en este escrito y volviendo sobre la pregunta-problema propuesta, de ¿qué papel juega el EP en las prácticas de los seguidores?, en forma de búsqueda de una hipótesis, puedo establecer que el EP juega un papel esencial en relación con esta práctica un doble papel, representado un ámbito tanto de posibilidad de existir, de posibilidades para perdurar, pero tambien de amenazas constantes.

Por un lado, las prácticas de los seguidores son esencialmente urbanas, no pueden ocurrir en otros espacios que no sean los exteriores urbanos, las calles de la ciudad. Su razón de ser es poder seguir y mantener proximidad con los sujetos que siguen (las bandas de cumbias y sus presentaciones), si alguna noche éstas no salen a la calle, si no se hacen presentes en el exterior urbano, la actividad de los seguidores pierde sentido.

Por otro lado, es este mismo espacio- que, por exterior abierto, amplio y de libre acceso- que se presenta como ámbito propicio y fértil para la actividad de los seguidores, el que los expone al resto de al encuentro y las críticas de los medios de comunicación y del resto sociedad, transformándose en un asunto de relevancia pública, en razón de estar en ese espacio que es la calle, y que ahora se entiende como ámbito público (aquí, refiriéndome al EP como espacio de sometimiento en público). Los seguidores no están solos en la calle, la comparten con los habitantes de la ciudad que puedan estar ahí afuera en el momento justo que éstos se hacen presentes. Todos ellos como viandantes, (los seguidores y cualquier otro sujeto en la calle) se ven sometidos a las iniciativas y apreciaciones de los otros copresentes (por ejemplo, de acusaciones de habitantes hacia los seguidores, o de agresiones de los seguidores hacia otros), y esto solamente es posible en la razón de estar compartiendo el mismo espacio, de estar en proximidad, y esto es impensable que ocurra en el ámbito privado.

Es en ese espacio exterior, de exposición y de comparecencia con extraños donde es fundamental saber estar, desplegar las correctas formas, modales, estrategias de cortesía y de cortejo para lograr agradar o no molestar al otro. Es en este limbo soñado- imposible- de armonía, igualdad, tranquilidad de comparecencia agradable, de ideales de la filosofía política hechos espacio tangible, donde las prácticas de los seguidores representan una amenaza constante, de incivilidad, demostrando no saber estar. Esto debido, no solamente por a los delitos concretos que puedan cometer, sino posiblemente tambien debido a marcas históricamente construidas en relación a quienes son y a lo que hacen: son jóvenes, y de las periferias, de sectores populares, en plena actividad ociosa (no productiva) ... En esto queda implicita la corrección, el ajuste a la norma del saber estar, necesarias para recuperar la tranquilidad a través de evacuar las posibilidades de conflicto y la molestia: qué deberían hacer, como lo deberían hacer, que aspecto deberían tener, y tal vez, hasta quienes deberían ser.

Pero este ámbito, más allá de su acepción normativa del sometimiento cortes, otra vez entendido como simples exteriores urbanos, como espacios abiertos habilitados para el encuentro y para todo tipo de posibilidades infinitas, es a la vez, el que permite la supervivencia de estas prácticas en el tiempo. Es el ámbito que somete a los sujetos a una anomia inducida, que imposibilita que sean reconocidos con exactitud, lo que imposibilita que el fenómeno sea encontrado más allá de cuando ocurre. La calle dificulta que sea atrapado en el mismo momento en que ocurre, ya que, ante algún tipo de amenaza, como puede ser la intervención policial, esa masa anómica, que es la seguidilla, se disgrega y dispara en todas direcciones, y en este gesto de desagregación cada seguidor, al no portar marcas visibles de su identidad seguidora, vuelve instantáneamente a ser todo eso que era antes de la seguidilla, tambien vuelve a ser un viandante cualquiera, y como tal, pura posibilidad. En este sentido vale preguntarse, fuera del momento de la seguidilla, ¿dónde está la seguidilla, ¿dónde están los seguidores?, ¿dónde se localizan?, en ningún lugar y en todos a la vez, cualquiera puede ser seguidor, la seguidilla más allá de la salida no existe como tal el resto del tiempo, solo vuelve a estar, a existir, cuando se manifiesta en la próxima salida, vuelve a ser solamente en el próximo encuentro de esos sujetos haciendo algo juntos, de la misma forma, en un mismo momento y con unos fines compartidos.

\section{BIBLIOGRAFÍA}

DE CERTEAU M. (2000). La Invención de lo Cotidiano I. México: ITESO

BARTOLOMÉ, M. (2006). Fronteras estatales y fronteras étnicas en América Latina. Disponible en http://ejournals.library.vanderbilt.edu/ojs/index.php/ameriquests/ article/view/41

DELGADO, M. (2007). Sociedades Movedizas. Barcelona: Anagrama. 
- (2011). El espacio público como ideología. Madrid: Los libros de la catarata

- (2013) El espacio público contra la calle. Quaderns de Recerca en Urbanisme, Barcelona, 1, 12-16

GONZÁLEZ C. E.; PANTALEÓN, J. Y CARTON de G. N. Editores (2016). Politics, Culture and Economy in Popular Practices in the Americas. Peter Lang. New York.

GUBER, R. (2012). La etnografía: método, campo, y reflexividad. Buenos Aires: Siglo Veintiuno

LEDESMA, E. (2017) Las prácticas de los seguidores de cumbia en la Ciudad de Corrientes. Jornadas de Comunicaciones Científicas y Tecnológicas FAU-UNNE, Resistencia, 5-6 de octubre de 2017 (en CD ISSN 2314-114X)

MÍGUEZ, D. y SEMÁN, P. Editores (2006): Entre santos cumbia y piquetes: las culturas populares en la Argentina reciente. Biblos, Buenos Aires.

\section{Fuentes consultadas}

Diario El Litoral (Corrientes Capital) https://www.ellitoral.com.ar/

Google Maps https://www.google.com.ar/maps

\section{Entrevistas}

Entrevista y mapeo junto a seguidor de Yiyo (Esteban). Mayo 2017 